\title{
LA-UR-19-28525
}

Approved for public release; distribution is unlimited.

Title:

Author(s):

Intended for:

Issued:
An Overview of Los Alamos Weapons Program

Port, Michael Denis

Ventura, Jonathan S.

Recruiting Event

2019-08-22 
Disclaimer:

Los Alamos National Laboratory, an affirmative action/equal opportunity employer, is operated by Triad National Security, LLC for the National Nuclear Security Administration of U.S. Department of Energy under contract 89233218CNA000001. By approving this article, the publisher recognizes that the U.S. Government retains nonexclusive, royalty-free license to publish or reproduce the published form of this contribution, or to allow others to do so, for U.S. Government purposes. Los Alamos National Laboratory requests that the publisher identify this article as work performed under the auspices of the U.S. Department of Energy. Los Alamos National Laboratory strongly supports academic freedom and a researcher's right to publish; as an institution, however, the Laboratory does not endorse the viewpoint of a publication or guarantee its technical correctness. 


\section{An Overview of Los Alamos Weapons Program}

Jon Ventura

Director Nuclear and Military Affairs

Office of the Deputy Director Weapons

Mike Port

Nuclear and Military Affairs

Office of the Deputy Director Weapons

- Los Alamos NATIONAL LABORATORY 
$21^{\text {st }}$ century geopolitical realities are challenging the existing security/political/economic structures and institutions

- Revanchist Russia

- Expansionist China

- Confrontational North Korea

- Turmoil in Europe

- Chaos in Middle East

- Nuclear proliferation

- Terrorism/Cyber

- Resource competition
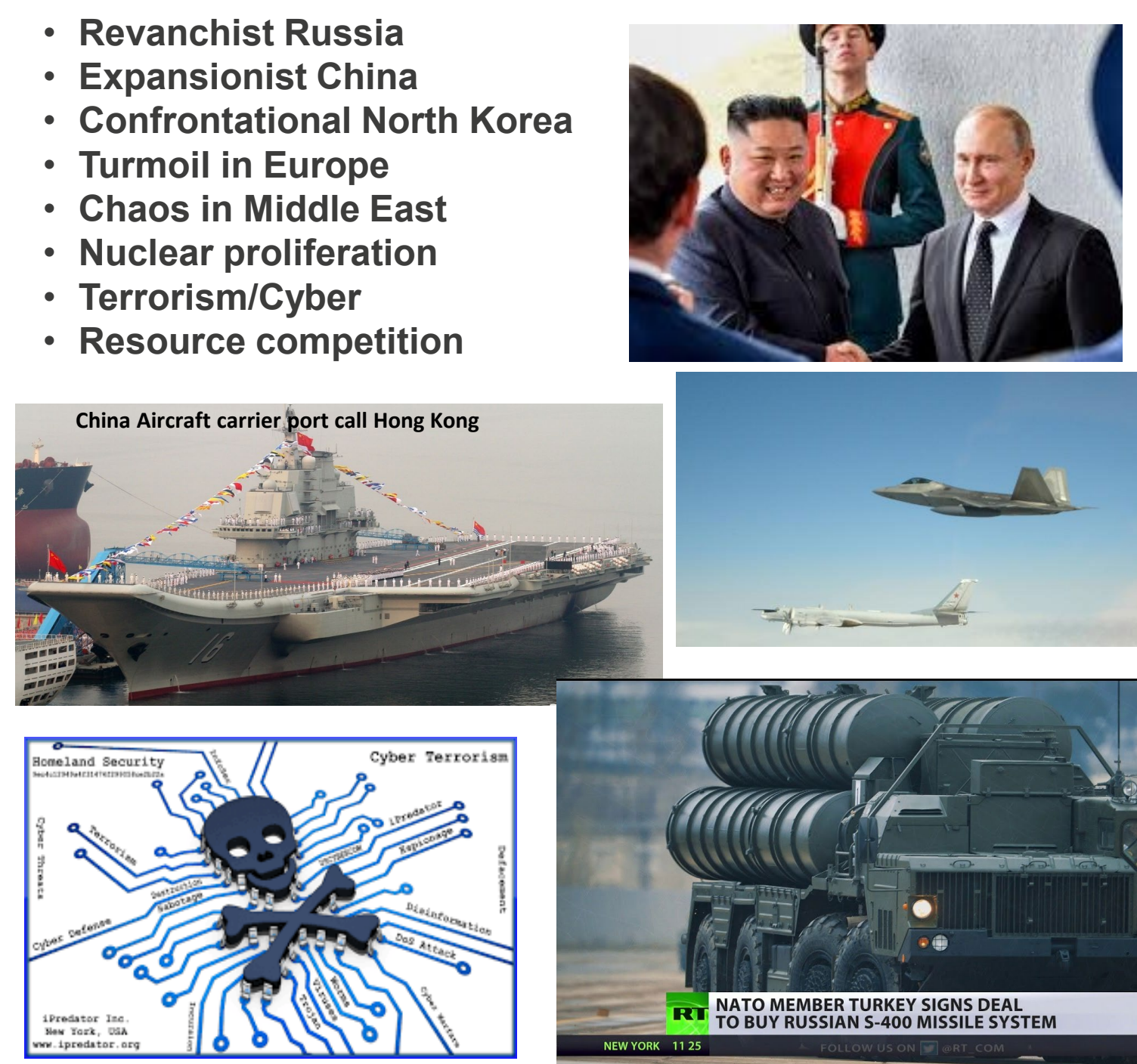

Iran's nuclear facilities

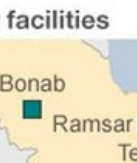

$$
\begin{gathered}
\text { Tehran } \square \text { Parchin } \\
\begin{array}{c}
\text { Arak } \% \text { Fordo } \\
\text { Natanz IRAN }
\end{array}
\end{gathered}
$$

IRAQ

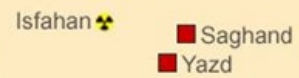

Research reactors

- Uranium mine

Military site

* Nuclear site
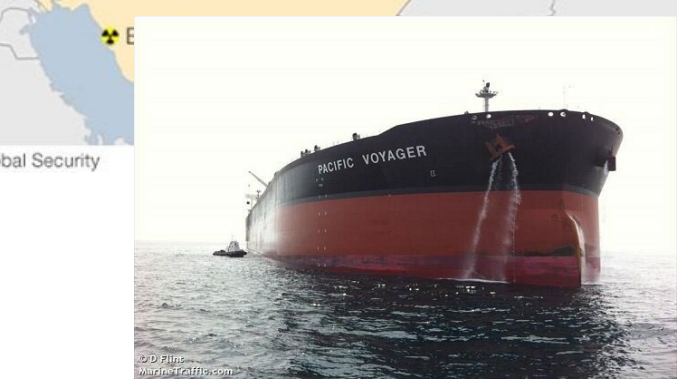

How

countries

compare

Population

Religion.

GDP per person

Life expectancy

Military Strength In InOA M PAKISTAN

Stratogic balance between India and Pakistan:

Armed forces (troops)

$\begin{array}{r}1.3 \text { million } \\ \hline\end{array}$

610,000

Combat aircraft

886

RI NATO MEMBER TURKEY SIGNS DEAL NATO MEMBER TURKEY SIGNS DEAL
TO BUY RUSSIAN S-400 MISSILE SYSTEM

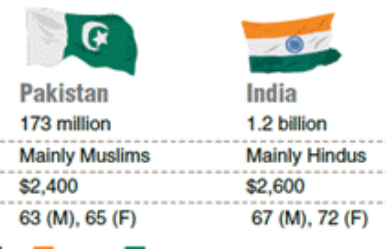

Surface warships

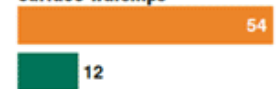

Submarines

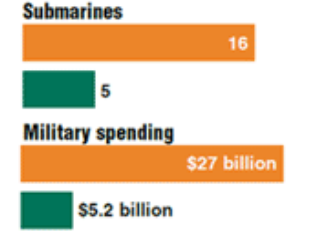




\section{The geopolitical realities demand the Laboratory's}

excellence for solutions to national security

- @12,000 employees

- 2200 PhDs

- 1100 veterans

- @1800 summer students

- $\quad$ 2.8B budget
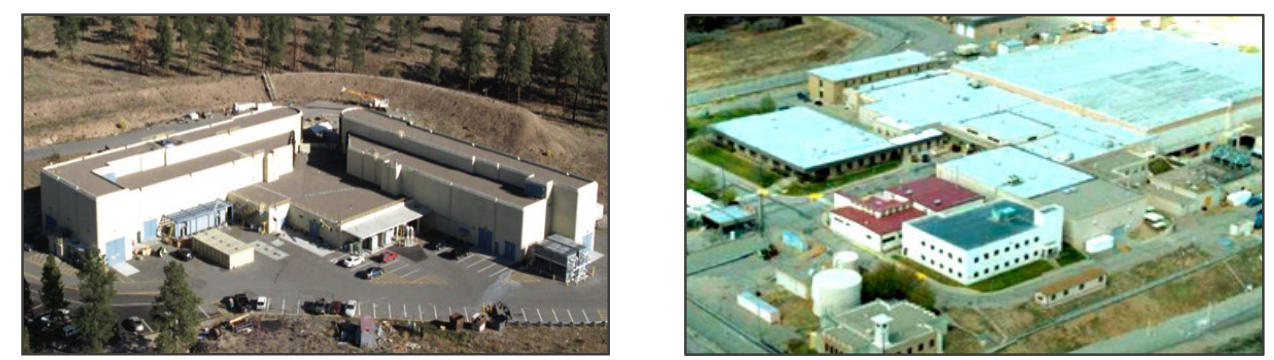

- 36 square miles

- 47 technical areas

- 1,280 buildings / 9M sq. feet - 11 nuclear facilities

- 268 miles of roads (100 paved)
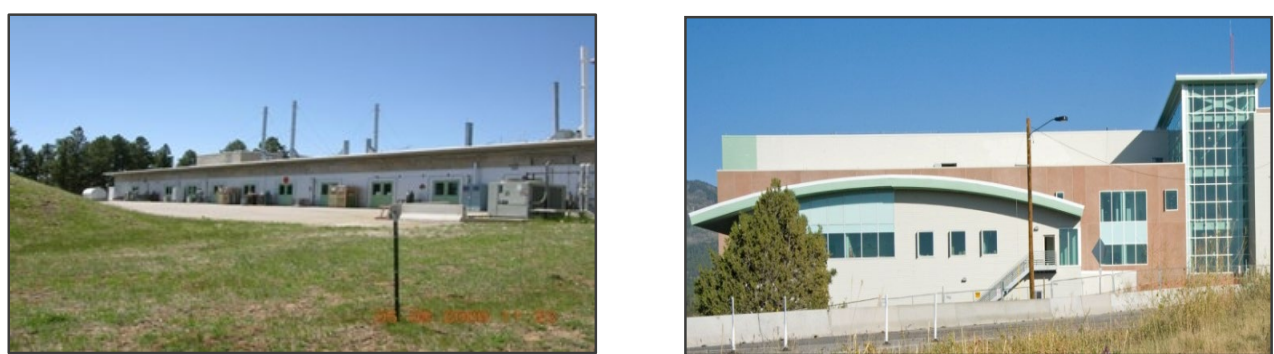

\section{LANL is hiring @1000 new employees annually}
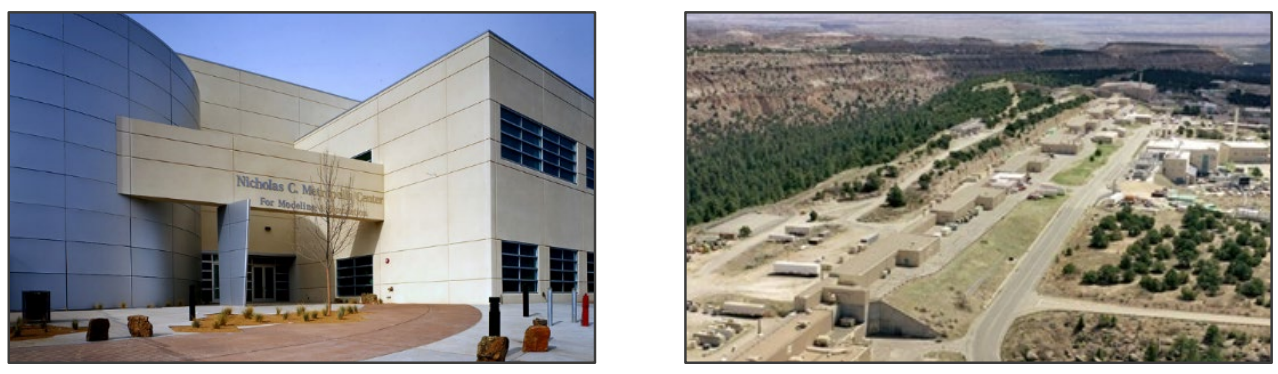


\section{LANL is the design laboratory for the majority of the Nation's on-alert deterrent}
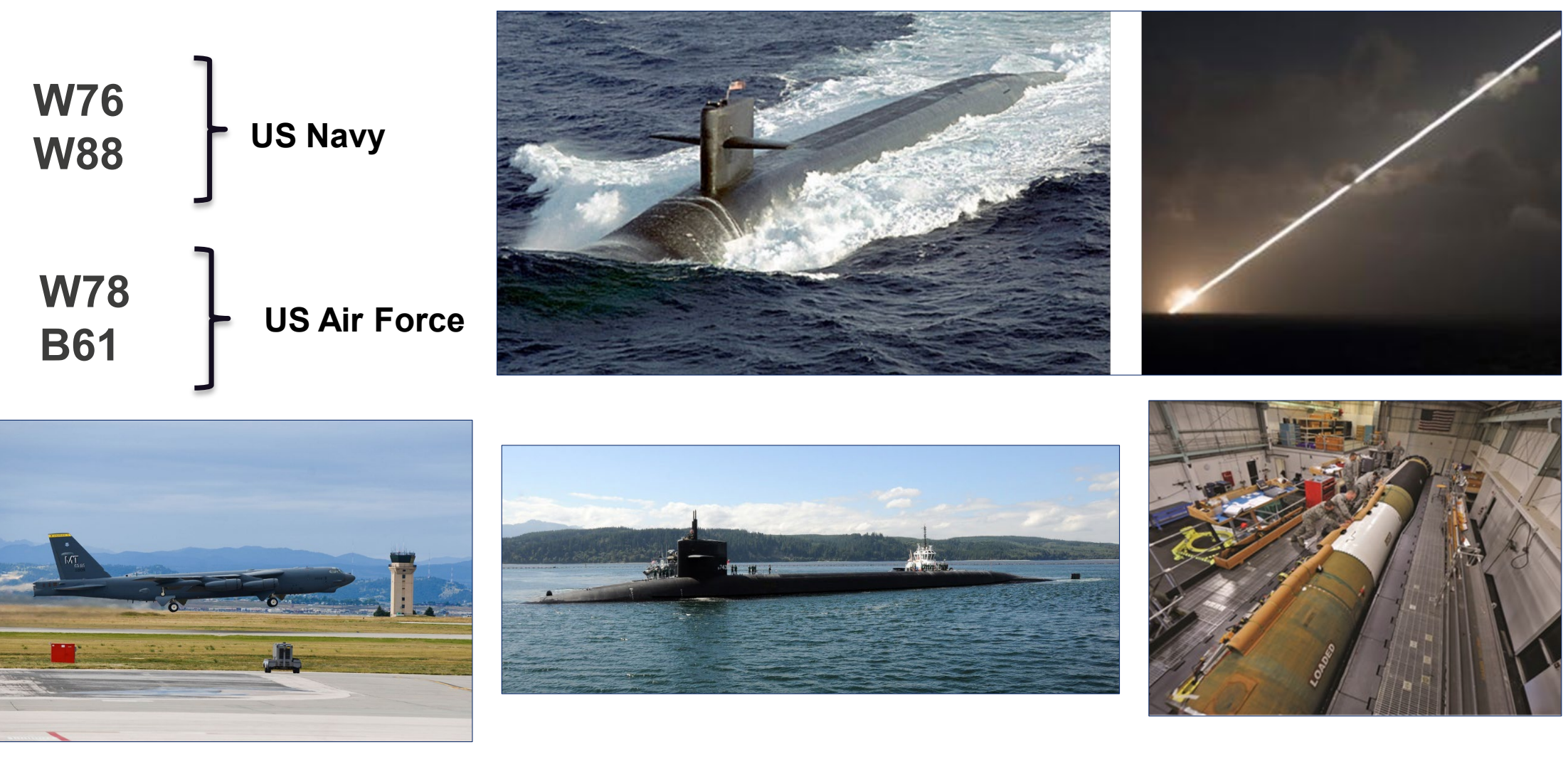

"Nuclear weapons have and will continue to play a critical role in deterring nuclear attack and in preventing large scale conventional warfare between nuclear armed states..."

Former Secretary of Defense Jim Mattis, Nuclear Posture Review 
Would you fly in it after its been parked for $20+$ years?

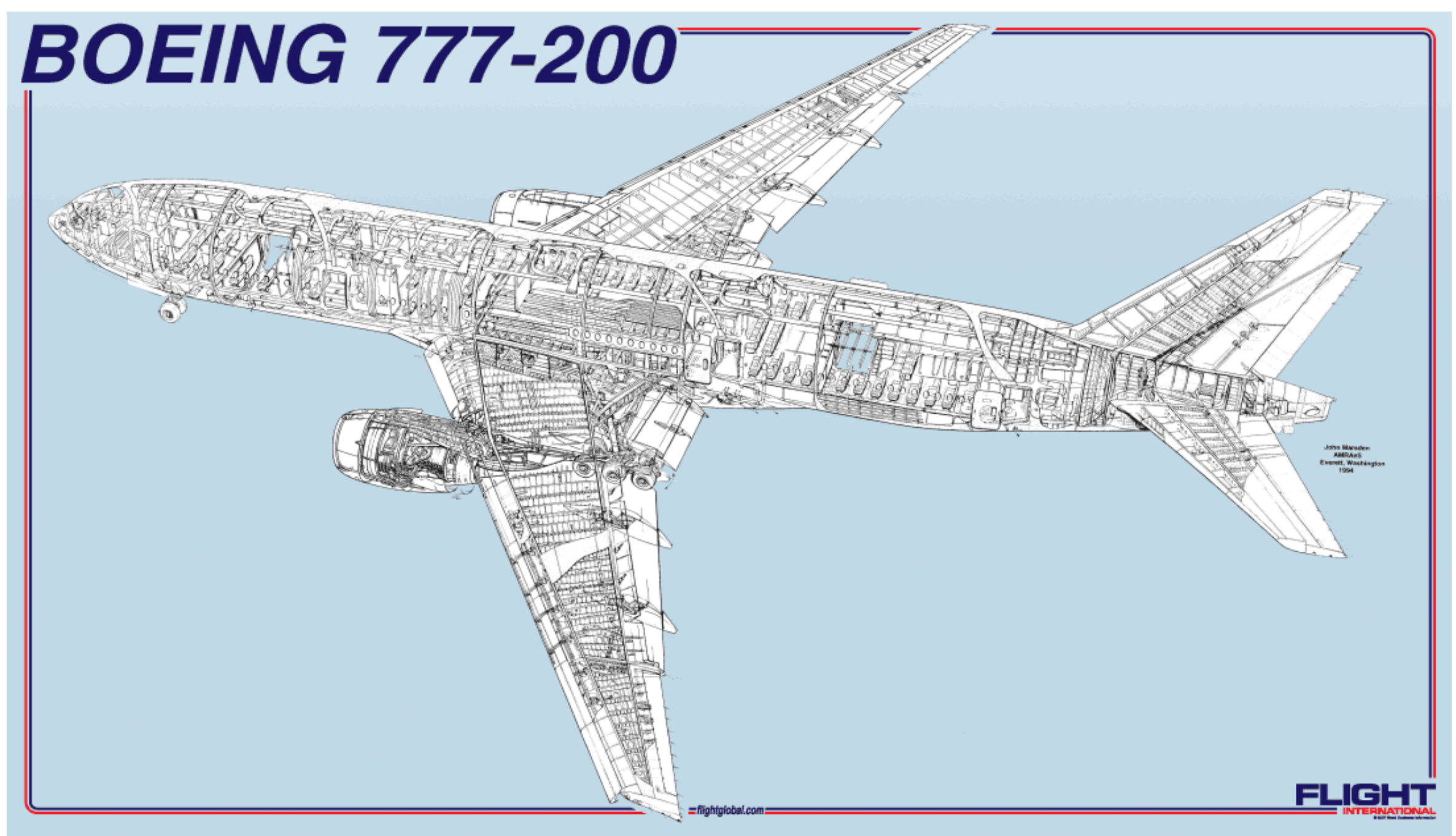




\section{Science, engineering and computations underpins all national}

security work of the laboratory

- Experiments

- 1000s experiments conducted annually to further our understanding and confidence in the stockpile

- Modeling and simulation

- World class computing hardware/software

- Designer judgement

- Experimental data used to check judgement

- Train next generation

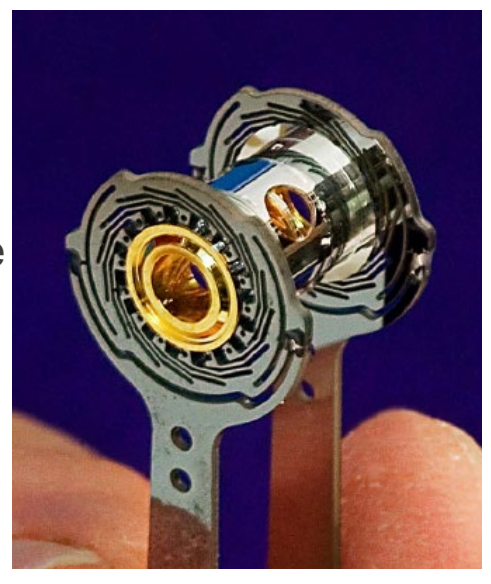

High Energy Density (HED) Experiments
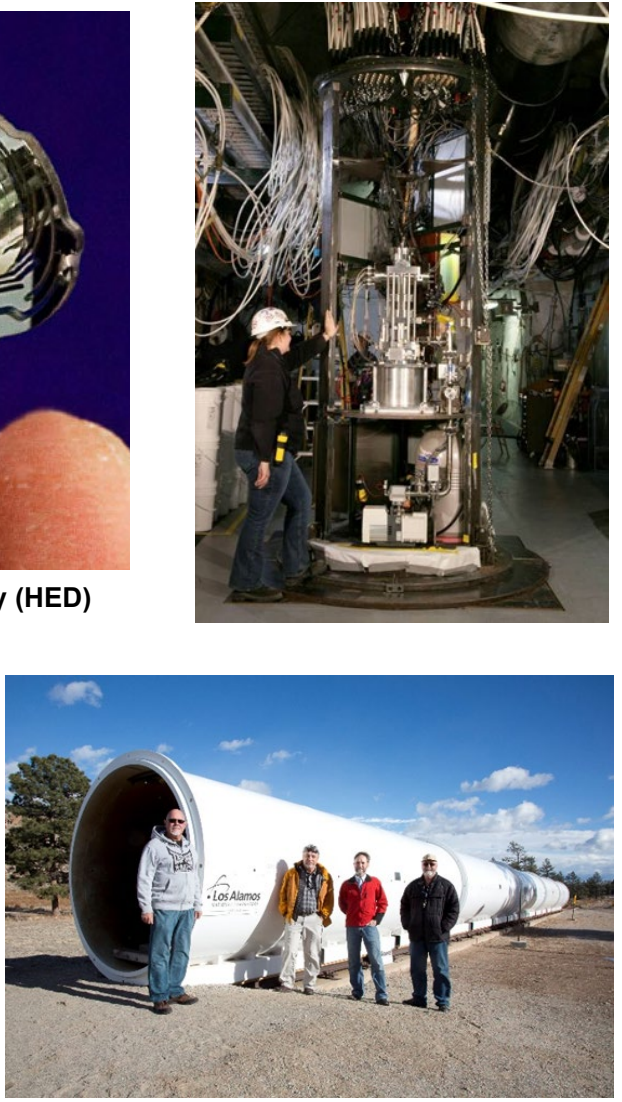
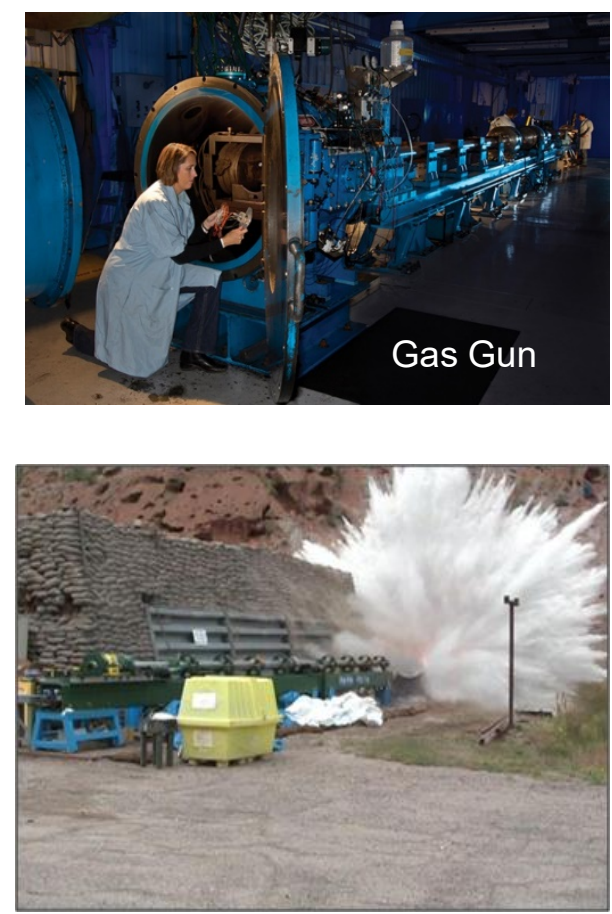

Large bore powder gun - measure differences in performance of weapon materials of interest

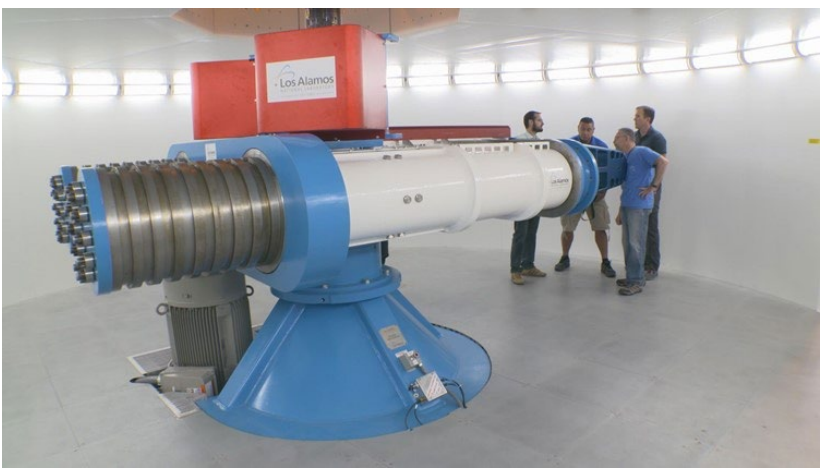




\section{World class radiographic capabilities supports LANL/LLNL}

weapons and global security programs

- DARHT world-class X-ray radiography for non-nuclear tests

- Axis I: single image

- Axis II: four images

- Experiments fully contained to reduce environmental impacts and increase shot rate
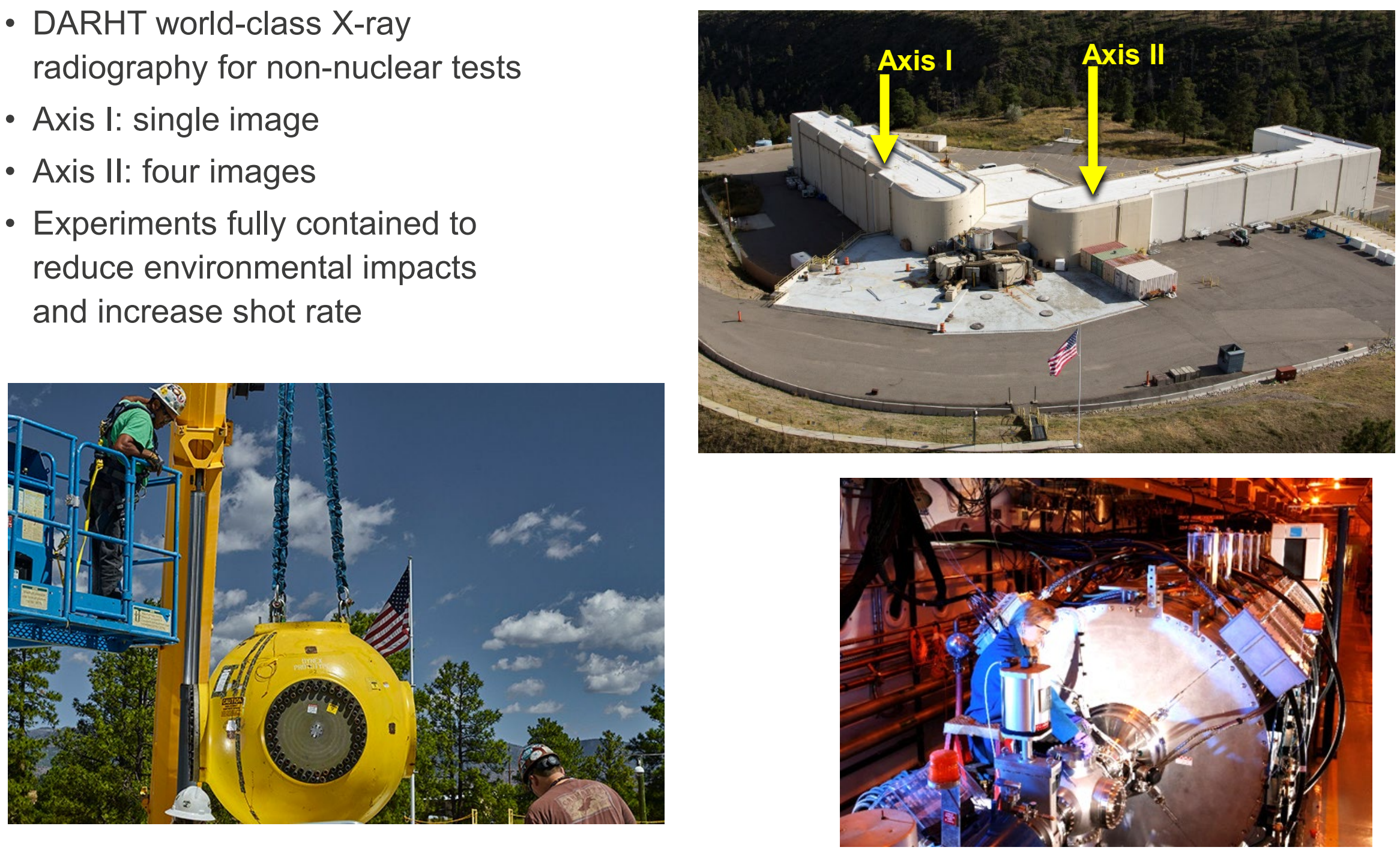


\section{Petascale Supercomputing is critical to Los Alamos' national security missions}

- Stockpile challenges are increasingly complex as systems continue to age

- DARHT, LANSCE etc provide large data sets to resolve stockpile challenges

- Data sets require ever more capable machines that can quickly process information

- Capacity and Capability machines

- Trinity

- Fire, Ice
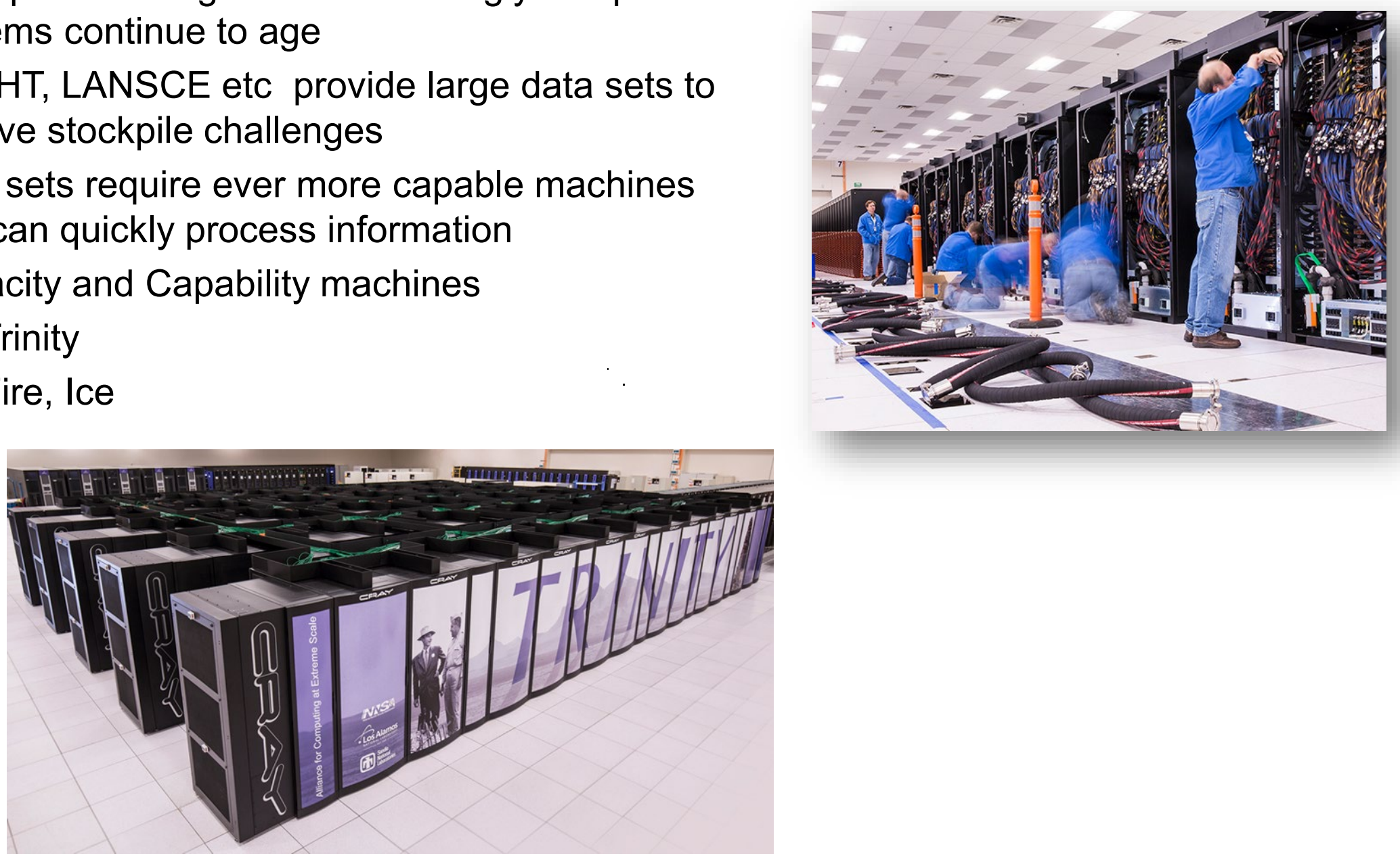


\section{Los Alamos: center for plutonium excellence and critical to science and security}

- Deliver parts for LANL experimental science

- Deliver parts for DoD Mission

- 30 pits per year 2030

- Partner with STRATCOM, Global Strike, USAF, USN.......

- Deliver parts for NASA and other federal agencies

- Provide technical options to meet new and emerging challenges

- IAEA training

- Additive manufacturing
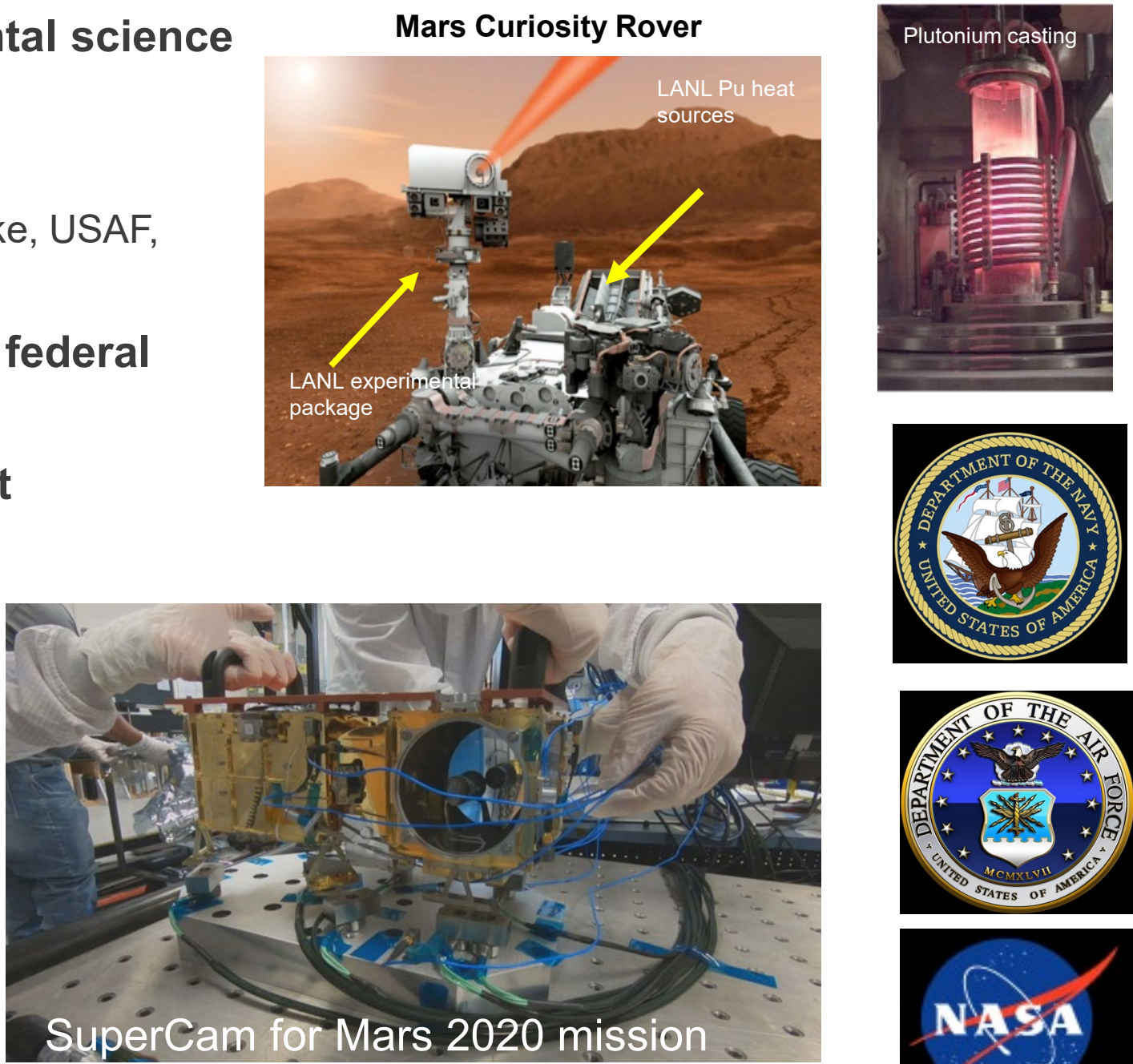

NSA 


\section{By law, Los Alamos Director reports on the state and}

health of the Nation's deterrent

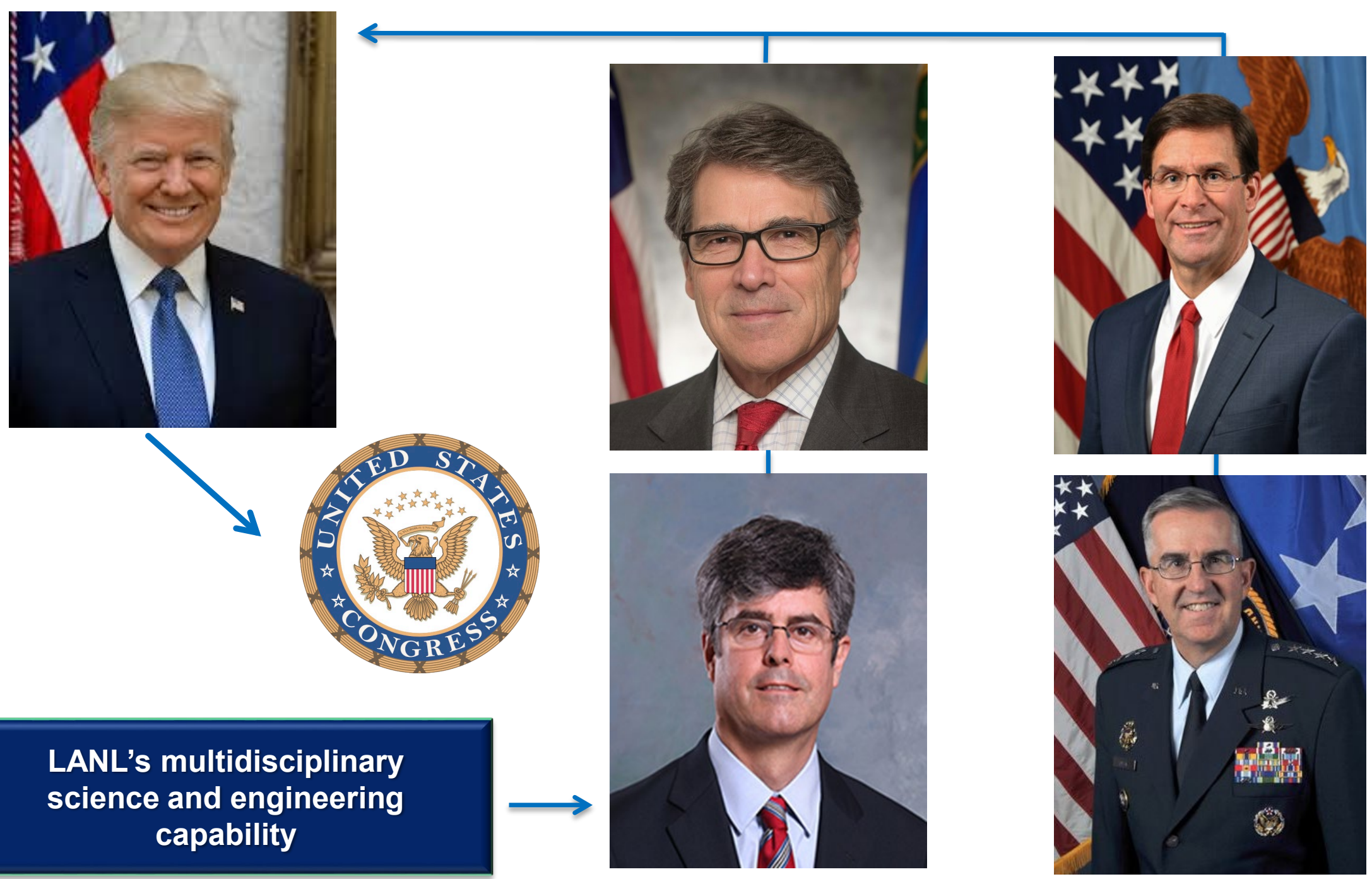




\section{A Final Thought}

"This Laboratory has always been something of wonder. Everyone one of you should be very proud that you are part of it. Take note it does wonderful things. Do well with it."

Roger Rasmussen Trinity eyewitness LANL employee 1944-2005

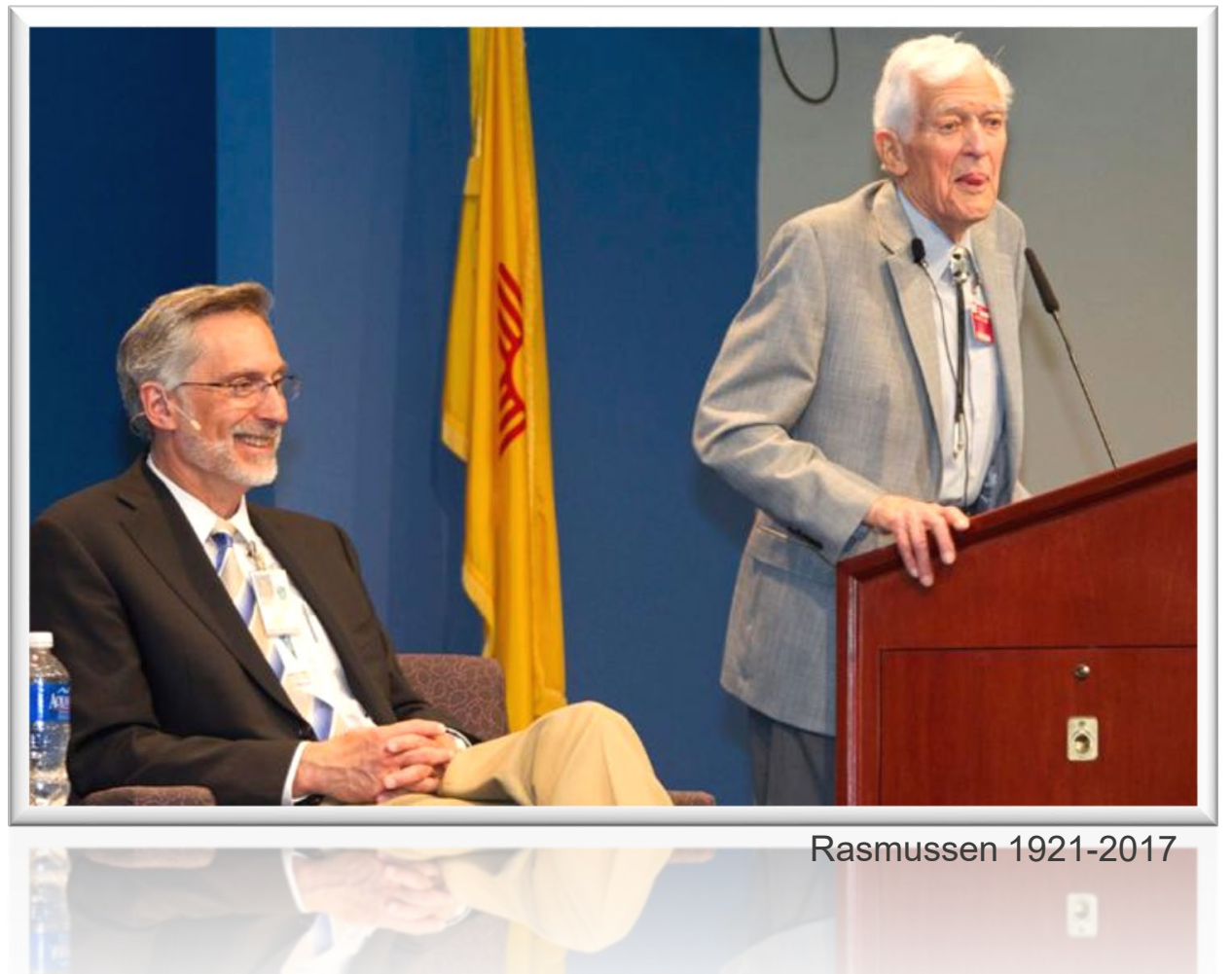

